\title{
„Wyjątek” jako kategoria opisu rzeczywistości
}

\author{
„Exception” as a category of reality description \\ Włodzimierz Lapis \\ Institute of Linguistics, Adam Mickiewicz University \\ Ul. Międzychodzka 5, 60-371 Poznań, POLAND
}

\begin{abstract}
What is an exception? Is the exception exceptional or common? Should we be engaged with an exception in this connection? Do exceptions simplify or complicate our lives? In this article we deal with the analysis of these problems and we make an attempt at answering all these questions. We also look for benefits which we can obtain referring to exceptions.
\end{abstract}

\section{Definicja wyjątku}

Do opisanie jakiegoś zbioru $X$ obiektów, celem ich wzajemnego rozróżnienia, używa się szeregu własności, którymi te obiekty mogą być opisane (np. w przypadku butów: rozmiar, materiał, typ, cena, kraj pochodzenia, ...) i nadaje im się na tych kategoriach odpowiednie (tj. przynależne im) wartości.

Możemy powiedzieć, że „dobrze opisaliśmy dany zbiór obiektów”, gdy dla dowolnego jego obiektu, podając wartości poszczególnych wyspecyfikowanych własności, jesteśmy w stanie jednoznacznie go zidentyfikować wśród pozostałych obiektów tego zbioru. Równoważnie możemy powiedzieć, że mamy dobrze opisany zbir obiektów, gdy żadne dwa jego elementy nie są tak samo opisane na służących do jego specyfikacji własnościach. Jeśli by jednak ten warunek nie był spełniony, wówczas - celem dobrego opisania owego zbioru obiektów - musimy dla jego elementów dodać co najmniej jeszcze jedną opisującą je własność, na której wszystkie dotychczas nierozróżnialne obiekty tego zbioru będą się różniły co do wartości.

Przy tego typu opisie, ze zrozumiałych względów (ekonomia!), jesteśmy zainteresowani optymalizacją liczby tak poszczególnych własności, jak i sumy mocy tych kategorii (można to rozpatrywać tak po potencjalnych wartościach własności, jak i rzeczywistych - tych, z którymi mamy do czynienia $\mathrm{w}$ danym zbiorze).

Rozpatrzmy obecnie dwie niezależne, jednak (co do skutku) równoważne sobie sytuacje.

\section{SYTUACJA}

Mając dany pewien ustalony zbiór $X$ (nasze uniwersum), często opisujemy nie tyle jego pojedyncze elementy (jak to robiliśmy powyżej), lecz dowolne (wieloelementowe) podzbiory tego zbioru. Wówczas taki nowy zbiór wymaga oddzielnej charakterystyki na tle owego uniwersum, aby móc dokładnie określić które obiekty z uniwersum są jego elementami, a które nie. Dokonuje się tego poprzez stwierdzenia typu: ,są to te obiekty rozpatrywanego uniwersum, które na kategorii A przyjmują wartość $\mathrm{a}_{3}$, a na kategorii $\mathrm{C}$ - wartość $\mathrm{c}_{7}$, $\mathrm{z}$ wyjatkiem tych obiektów, które na kategorii $F$ przyjmują wartość $\mathrm{f}_{5}$ lub $\mathrm{f}_{12}$ ". 


\section{SYTUACJA}

W ustalonym zbiorze (zwanym uniwersum) wyróżnijmy jakiś podzbiór (np. w zbiorze zdań zbiór pytań; w zbiorze wszystkich słów, zbiór tych które zaczynają się /w wymowie/ na u, itp.). Wówczas zwykle możemy określić pewne reguły, którym podlegają elementy tego podzbioru. Często zdarza się jednak, że musimy się wtedy jeszcze posiłkować pojęciem wyjątku, gdyż nie wszystkie elementy owego podzbioru podpadają pod te reguły.

Tak więc poprzez reguły i wyjątki:

- w I sytuacji, z określonego uniwersum, wyodrébniliśmy pewien zbiór i za pomocą (odpowiednio dużej liczby) reguł i wyjątków, zdefiniowaliśmy go,

- $\quad$ w II sytuacji, majac już wyodrebniony jakiś zbiór (być może nawet jakoś zdefiniowany), przy pomocy pojęć „reguła” i „wyjątek”, określamy pewną (lub pewne) jego własność(ci).

W obu tych sytuacjach, od występujących w nich reguł, mogą więc też występować pewne wyjątki, na które składają się obiekty wymykające się tym regułom. Innymi słowy możemy więc powiedzieć, że wyjątkowi podlegają te obiekty, które (w danej sytuacji) nie podlegają regułom (nie poddają się opisowi przy pomocy reguł, są od nich odstępstwem). Wyjątki muszą więc być zawsze rozpatrywane w stosunku do reguł, które naruszaja; inaczej nie sposób ich rozpatrywać. Tak więc, choć - co prawda - mogą być reguły bez wyjątków, to jednak wyjątki bez reguł - już nie.

W obu wyszczególnionych wyżej sytuacjach, pojęcie wyjątku może więc być nam niezmiernie pomocne. Co prawda można tak formułować reguły, aby nie było potrzeby używania pojęcia „wyjątek”, jednak były by one wtedy o wiele bardziej skomplikowane.

\section{Aspekty pojęcia ,wyjątek"}

Zwróćmy tu uwagę na fakt, że tak pojęcie „,reguła” jak i „wyjatek” możemy rozumieć na dwa sposoby - jako zasada lub jako zbiór, określajace odpowiednio co potencjalnie ( $\mathrm{tj}$. przed wykluczeniem) jest lub (tym razem kategorycznie) czego (w wyniku tego wykluczenia) nie ma w omawianym zbiorze. Zobaczmy, jakie konsekwencje niesie ze sobą takie postawienie sprawy.

1. Jeśli wiemy na jakim uniwersum operujemy (które definiowane jest zawsze jako zbiór), i na nim mamy wyodrębniony jakiś podzbiór (a więc też zbiór), to wówczas $\mathrm{w}$ każdej z dwóch wyróżnionych w poprzednim paragrafie sytuacji - tak reguła jak i wyjątek mogą być określone zarówno jako zbiór, jak i (w oparciu o aksjomat wyróżniania) jako zasada (patrz tabela 1).

Tabela 1. Możliwe zestawienia sposobów określania regut i wyjątków

\begin{tabular}{|c|c|c|c|c|c|}
\hline LP & uniwersum & podzbiór & reguła $(\mathrm{y})$ & wyjątek(ki) & może tak być? \\
\hline 1 & $\mathrm{~S}$ & $\mathrm{~S}$ & $\mathrm{~S}$ & $\mathrm{~S}$ & tak \\
\hline 2 & $\mathrm{~S}$ & $\mathrm{~S}$ & $\mathrm{~S}$ & $\mathrm{R}$ & tak \\
\hline 3 & $\mathrm{~S}$ & $\mathrm{~S}$ & $\mathrm{R}$ & $\mathrm{S}$ & tak \\
\hline 4 & $\mathrm{~S}$ & $\mathrm{~S}$ & $\mathrm{R}$ & $\mathrm{R}$ & tak \\
\hline
\end{tabular}

$$
\mathrm{S}-\text { zbiór (od: set) } \quad \mathrm{R} \text { - zasada (od: rule) }
$$

2. Zauważmy, że to, czym zwykle określamy wyjątek (konkretną sytuację) de facto nią nie jest. Nie można np. powiedzieć, że zapis przez $o$ wyrazu ów, to wyjątek od reguły „na początku wyrazu może wystapić jedynie u (u otwarte)". Jest to jedynie ,jeden z elementów wyjątku” zbioru zwanego wyjątkiem, poprzez bezpośrednie określenie, że jest on jego elementem lub że podlega pod zasadę określająca co stanowi, a co nie stanowi wyjątku. 
3. Reguła wcale nie musi być „dobrze dopasowana” do określanego pojęcia. Tak więc np. zero możemy zdefiniować jako każdą (de facto jedyną) liczbę całkowitą nieujemną (reguła nieskończenie wiele elementów), która nie jest dodatnia (wyjątek - również nieskończenie wiele elementów). Niedopasowanie reguły w konsekwencji oznacza więc dużą liczebność tak rozumianego (a więc jako zbiór lub jako zasada) wyjątku. Nieraz jednak takie postępowanie jest celowe ze względu na łatwość definiowania tak reguły, jak i wyjątku.

4. Na wiele sposobów można definiować pojęcia, poprzez dobór różnych reguł i (odpowiednio dopasowanych do nich) wyjątków.

5. Z jednej strony celowy jest dobór takich reguł, aby były jak najmniej odległe od opisywanego pojęcia (a co za tym idzie, aby zbiór wyjątków był jak najmniej liczebny), z drugiej zaś strony, aby opis reguł i wyjątków był jak najbardziej prosty. Celowym wydaje się znalezienie stosownego kompromisu między tymi dwoma postulatami.

6. Ponieważ reguła (jako taka) nie musi być bezwarunkowa, zatem można przyjąć, że reguła (warunkowa) będzie dotychczasowa reguła bezwarunkowa z dołączonym do niej odstępstwem - wyjątkiem od tej reguły. Od tak otrzymanej reguły nie będzie już wyjątków (gdyż ma już je „w sobie").

7. Przypatrzmy się (stosowanej w matematyce) definicji pojęcia „prawie na pewno”. Oznacza ono: „zawsze, poza zbiorem miary zero”. Jeśli jednak nasze uniwersum składa się ze skończonej liczby elementów (np. 10), wówczas usunięcie skończonej liczby elementów może oznaczać:

1) nie usunięcie żadnego (nadal jest 10),

2) usunięcie części: mniejszej (np. 3), większej (np. 7) lub połowy (5),

3) zostawienie jednego elementu,

4) usunięcie wszystkich (10) elementów.

W każdym z tych przypadków możemy powiedzieć, że „prawie na pewno” coś zachodzi, mimo że zachodzi to od $0 \%$ ( $\mathrm{tj}$. wcale!) poprzez jedno wystapienie, następnie niewiele, połowę, większość, aż wreszcie do $100 \%$. Jest oczywiste, że jesteśmy zainteresowani, aby słowa określały takie sytuacje, jakich się po nich spodziewamy. Stąd też sugestia, aby:

- $\quad$ słowa zwykle używać gdy coś zachodzi co najmniej w 2/3 przypadków,

- a słowa przeważnie - gdy zachodzi to w ponad 50 \% przypadków.

Jeśli zaś nie wiemy, w jakim wymiarze coś zachodzi - najlepiej jest stosować neutralne pod tym względem słowo zasada (dla określenia sytuacji jak w 2. punkcie niniejszego paragrafu).

\section{Aspekty zagadnienia wyjątku}

W poprzednim paragrafie zajmowaliśmy się zagadnieniem „,co znaczy wyjątek”. Z kolei w tym paragrafie, rozpatrzymy specyficzne sytuacje, w których on występuje.

a) o wyjątku od wyjątku

Zastanówmy się najpierw, czy wyjątek od wyjątku jest wyjątkiem. Otóż, w myśl dotychczasowych rozważań - nie! Powoduje bowiem dołożenie elementów do określanego pojęcia, a nie ich ujęcie. Jednak analizując sprawę szerzej (tj. podchodząc do wyjątku nie jako do pojęcia, lecz jako do całego zagadnienia), należy uznać, że tak.

Załóżmy więc, że mamy jakąś regułę. Ma ona wyjątki. Od tych wyjątków mogą jednak istnieć wyjątki, i od tych wyjątków również (itd.). Najlepiej jest przyjąć tu, że wyjątki, to też pewne reguły, jednak wykluczające (od reguły zdefiniowanej jak w poprzednich paragrafach lub od innej reguły-wyjątku). 


\section{PRZYKŁAD}

Przypatrzmy się poniższemu schematowi blokowemu (rys. 1). Przedstawia on algorytm służący do orzekania czy (w kalendarzu gregoriańskim) dany rok $x$ jest przestępny czy też zwykły.

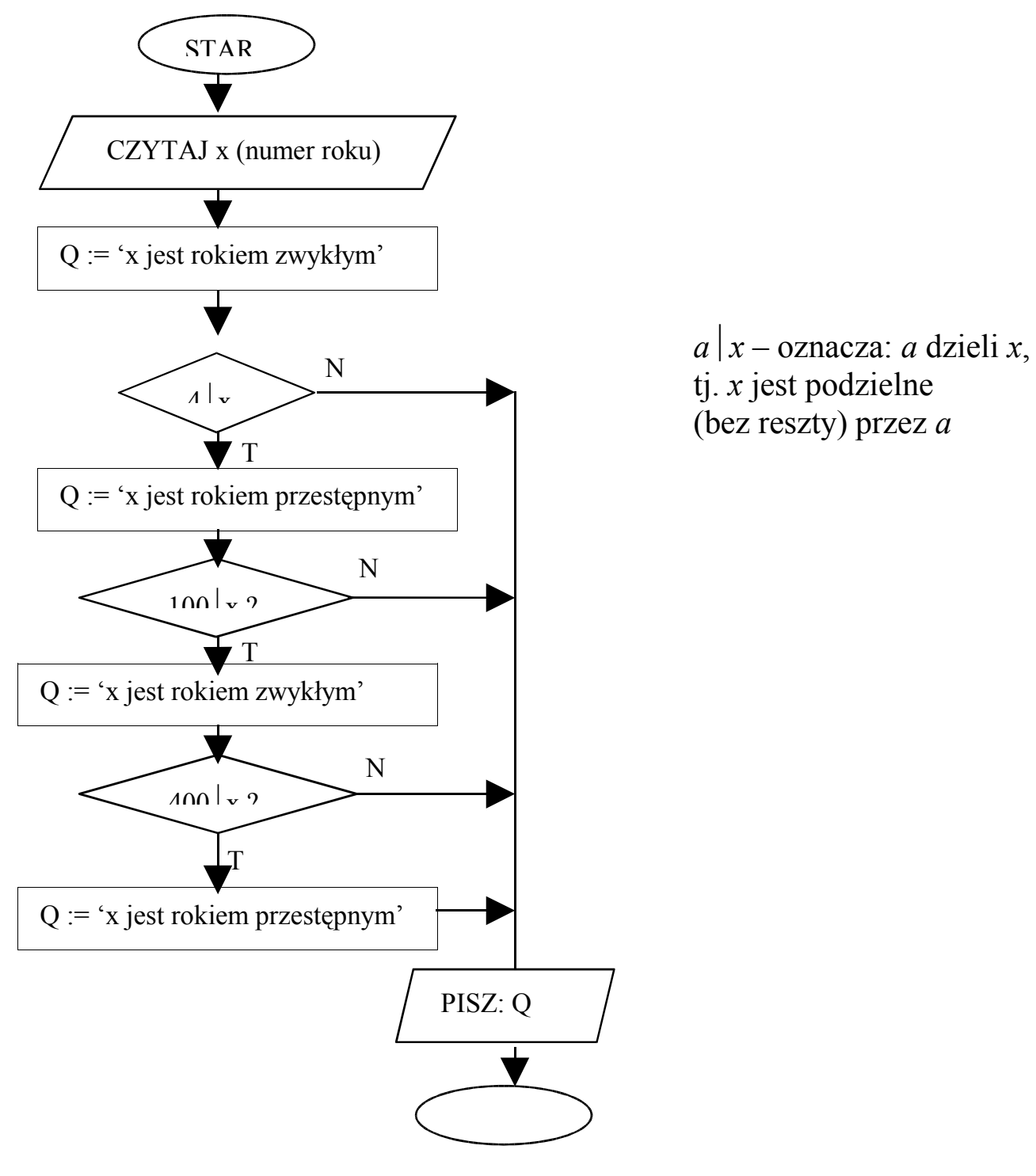

Rys. 1. Schemat blokowy algorytmu sprawdzania przestępności roku

$\mathrm{Na}$ podstawie Rys. 1 możemy podać definicję roku przestępnego (w kalendarzu gregoriańskim). Otóż, przestępnym jest ten rok:

1) którego numer jest podzielny przez 4 ,

2) za wyjątkiem gdy jego numer jest podzielny przez 100,

3) chyba że jego numer jest podzielny przez 400 , bo wtedy jest on jednak przestępny (jest to wyjątek od poprzedniego wyjątku).

Widzimy, że w każdej z tych linii podana jest pewna zasada - reguła, przy czym możemy je opisać następująco:

1) $R_{0}$ - reguła podstawowa, analogicznie: zbiór lat podzielnych przez 4 ,

2) $R_{l}$ - reguła, wyjątek od $R_{0}$, analogicznie: zbiór lat podzielnych przez 100 ,

3) $R_{2}$-reguła, wyjątek od $R_{l}$, analogicznie: zbiór lat podzielnych przez 400 , 
Przy czym przez pojęcie ,rok podzielny przez $n$ ” rozumiemy rok, którego nazwa $=$ numer jest liczbą podzielną bez reszty przez $n$.

W sumie, jeśli oznaczymy: $P$ - rok przestępny (a właściwie zbiór lat przestępnych), to otrzymamy: $\quad P=R_{0} \mid\left(R_{1} \backslash R_{2}\right)$.

Zobaczmy, jak ta równość będzie wyglądać na diagramie Venna:

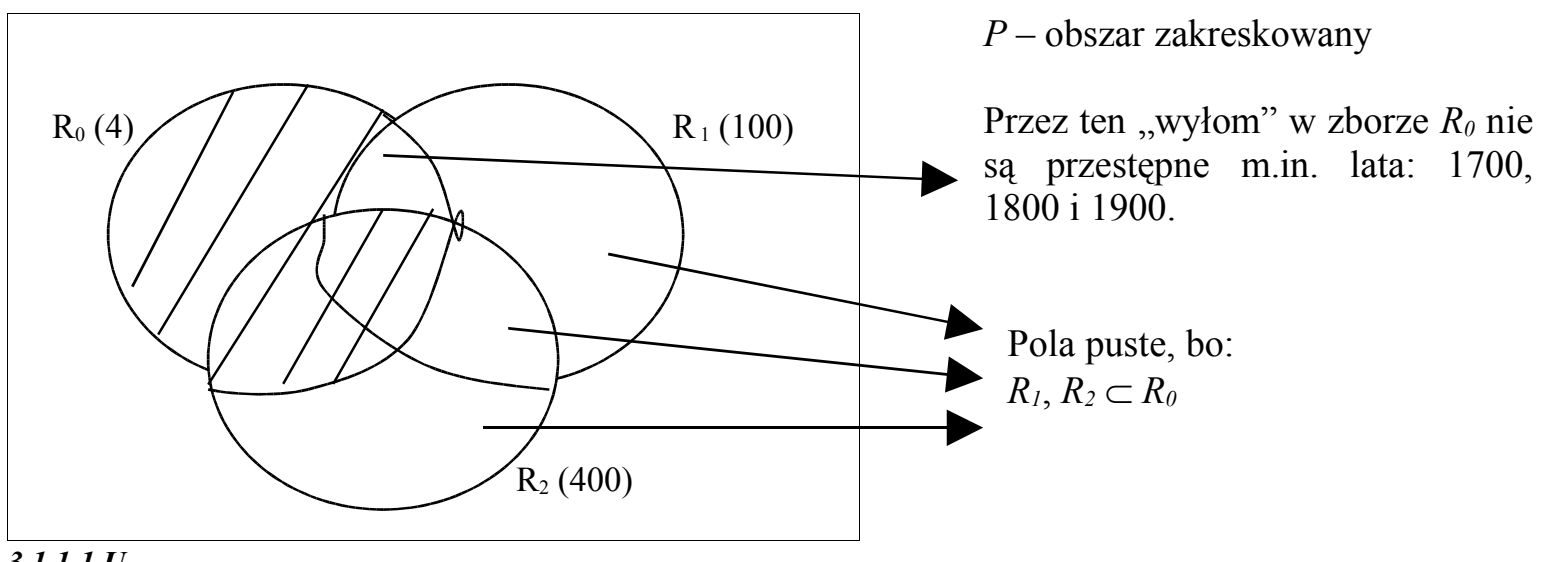

3.1.1.1U

Rys. 2. Diagram Venna prezentacji reguły określania lat przestępnych

Mamy tu więc wszystko sprowadzane do reguł i operacji na nich. Jeśli zaś koniecznie chcemy operować na pojęciu „wyjątek”, to możemy przyjąć, że $R_{0}$ - to reguła podstawowa, a pozostałe reguły - to wyjątki (odpowiednio takiego rzędu, jakim numerem są opatrzone).

b) o niedefiniowaniu pewnych obiektów

W matematyce, definiując dowolną funkcję, należy podać jej dziedzinę - zbiór argumentów, dla których jest możliwe jej określenie. Tak np. funkcję $y=x^{-1}(=1 / x)$ określa się dla dziedziny $D=R \backslash$ $\{0\}$, ze względu na niemożność dzielenia przez zero. Tutaj niedefiniowalność liczby o wartości $1 / 0$ wpłynęła na uczynienie zera (a właściwie $\{0\}$ ) wyjątkiem w dziedzinie funkcji $y=x^{-1}(=1 / x)$.

c) o instrukcjach warunkowych $\mathrm{w}$ informatyce

W informatyce, przy programowaniu, zjawisko wyjątku określa się za pomocą instrukcji warunkowej. Można to zrobić na dwa sposoby (zobaczmy na konkretnym przykładzie):

1) $\mathrm{k}:=3$; if $\mathrm{m}>30$ then $\mathrm{k}:=5$; ,

2) if $\mathrm{m}<=30$ then $\mathrm{k}:=3$ else $\mathrm{k}:=5$; ,

2 ) if $\mathrm{m}>30$ then $\mathrm{k}:=5$ else $\mathrm{k}:=3$; .

Każda z tych linii opisuje dokładnie tę samą sytuację, jednak realizowaną w inny sposób (choć za każdym razem za pomocą instrukcji warunkowej). Przypatrzmy się im bliżej.

$\mathrm{W}$ przypadku 1) mamy regułę ( $\mathrm{k}:=3$;) i od niej wyjątek (if $\mathrm{m}>30$ then $\mathrm{k}:=5$;). W przypadku 2 ) i 2') od razu mamy pełną instrukcję warunkową, która jest „rozbudowana regułą”. W ten sposób pozbyliśmy się więc wyjątków, jednak reguły są mniej czytelne - nie widzimy, co jest częstsze (bardziej regularne, jest regułą w powszechnym rozumieniu), a co wyjątkiem (sytuacją rzadsza). Dodajmy, że choć przypadek 2') jest ,z kształtu” bardziej podobny do przypadku 1) (bezpośrednio wskazuje, kiedy zachodzi wyjątek, a kiedy reguła w rozumieniu z punku 1)), to jednak przypadek 1) lepiej jest oddawany (,co do struktury”) przez przypadek 2) niż przez przypadek 3) (od lewej do prawej zachowany jest tok prezentacji). 
Ta sama zasada (,instrukcji warunkowej”), z powodzeniem może nam posłużyć jako swoiste kryterium budowy reguły, jak to mamy np. w przypadku stwierdzenia: na początku wyrazu zawsze piszemy $u$ (,,u" otwarte), chyba że są to wyrazy ów lub ósmy (lub dowolne ich formy fleksyjne), bo wtedy już tak nie jest (tj. nie piszemy ich przez $u$ lecz przez $o$ ).

\section{O wyjątkowości}

Ze szczególnym przypadkiem wyjątku mamy do czynienia wtedy, gdy jego moc równa się jeden (zgodnie z wcześniejszymi uwagami, za wyjątek przyjmujemy tu zbiór wszystkich przypadków będących odstępstwem od reguły). Składa się więc na niego tylko jeden - można by rzec: incydentalny - przypadek. W języku angielskim mamy stosowne słowo na określenie takiej sytuacji: unique - jeden, unikalny, jedyny w swoim rodzaju.

Jak powiada pewne polskie przysłowie: ,nie ma reguły bez wyjątków”. W myśl tego przysłowia, „wyjątkowość" jest więc powszechna. Nie jest więc wyjątkiem bycie wyjątkiem. Prędzej niebycie nim może być wyjątkiem, ale wtedy z tegoż powodu jest wyjątkiem! Cała rzecz jedynie w tym, na jakim poziomie „wyjątkowości” się poruszamy.

Choć więc wyjątek nie jest wyjątkowy, to jednak za każdym razem wzbudza zainteresowanie, czy też zadziwienie swoją „odmiennością” na tle innych obiektów danej kategorii - jest uznawany za swego rodzaju ,odmieńca”.

W języku naturalnym, gdy chcemy wyrazić, że mamy do czynienia $\mathrm{z}$ jednym z wielu wyjatków, możemy powiedzieć „,czarna owca”. Z kolei w przypadku, gdy chcemy dać wyraz naszemu przekonaniu, że jest to jedyny wyjatkowy obiekt, mówimy „,biały kruk”. Społeczne konotacje tych określeń oznaczają, że ,jedyny” jest pożądany (ów „biały kruk”), a wyjątek ,jeden z wielu” („,czarna owca”) - już nie! Wystarczy mieć jednego „dziwaka” jako ciekawostkę; większa ich liczba jest już zbyteczna i całkiem niepotrzebna.

Podsumować nasze rozważania możemy więc w następujący sposób: choć wyjątek jest wyjątkowy (różni się czymś od pozostałych obiektów danej kategorii), to jednak samo zjawisko wyjątku nie jest czymś wyjątkowym (jest powszechne; brak wyjątku jest raczej wyjątkiem - tak np. wśród języków tylko esperanto ma bezwyjątkową gramatykę).

\section{Podsumowanie i ostateczne wnioski}

Gdyby tylko dowolne sytuacje można było opisać jedynie przy pomocy prostych reguł - wówczas nie trzeba by się odwoływać do pojęcia „wyjątku”. Ponieważ jednak tak nie jest - wyjątki są niezmiernie pomocne, gdyż de facto upraszczają opis (ten, który byłby konieczny gdybyśmy nie stosowali wyjątków, a więc wykonany jedynie przy pomocy skomplikowanych reguł).

Dodajmy, że ponieważ sytuacje naturalne (z którymi na co dzień mamy do czynienia) są pełne wyjątków, więc naturalnym jest, aby do ich opisu wykorzystać pojęcie ,wyjątku”. Daje nam to dodatkowo „naturalny opis”, a więc oddawany w taki sposób, w jaki widzimy daną sytuację (co oczywiście - też jest korzystne). 